\title{
Drug Rash with Eosinophilia and Systemic Symptoms (DRESS) or Stevens-Johnson Syndrome (SJS): Does the Name Matter!
}

\author{
Awad Magbri* and Harshit Seth \\ Dialysis Access Center of Pittsburgh, PA \& Life-care Hospital, Pittsburgh, USA
}

*Corresponding author: Awad Magbri, MD, FACP, Dialysis Access Center of Pittsburgh, PA \& Life-care Hospital of Pittsburgh, PA, USA, E-mail: elmagbri@hotmail.com

\author{
Keywords \\ Rash, Eosinophilia, DRESS, Steven-johnson syndrome-toxic \\ epidermal necrolysis, AGEP, SCARs, Hypersensitivity drug \\ reaction, SHARE syndrome
}

\section{Case}

The case is of 23-year-old Caucasian male who fell from 30 feet height in a suicidal attempt. He presented to the hospital with fever, generalized macula-papular rash, and malaise. He was discharged initially to LTAC for continued recovery. After 3 weeks in the LTAC he developed pinhole infection of his hip that was reported methicillin resistant staphylococcal infection (MRSA) positive and was started on Vancomycin. After 5 days in the Long-term acute rehab center (LTAC), where he developed a generalized rash on his chest that was pruritic and erythematous but not painful. The rash became progressively worse spreading to the upper thighs. The patient was switched to linezolid out of concern for drug rash with vancomycin. This was continued for 3 days and then stopped. The patient was given a dose of levofloxacin and steroid, however, due to increasingly high fever, rash progressing to the face with facial edema, and tachycardia to 160 's, the patient was transferred to acute care facility. Patient has had multiple blood cultures and wound cultures of elbow that have been negative. He was evaluated by the psychiatrist at the LTAC and was started on aripiprazole $5 \mathrm{mg}$ QHS.

His electronic record showed that he had positive wound culture that grew MRSA. His CBC showed $12 \%$ eosinophilia, anemia with $\mathrm{Hg}$ of $9.7 \mathrm{~g} / \mathrm{dl}$, but no leukocytosis. Normal complete metabolic panel and liver func- tion tests. A skin biopsy showed eosinophilic infiltration throughout the dermis. The course is consistent with DRESS syndrome or SJS/TEN. His complement levels (C3, C4), rheumatoid factor, cryoglobulin, and further blood cultures were negative.

He developed DVT during his stay at the LTAC and was started on Coumadin with therapeutic INR. His examination revealed normal Cardiovascular, respiratory, and abdominal examination. His exposed hardware of the right elbow showed on infection, however, his hip pin site repeatedly grew MRSA infection and he was continued on linezolid. He was treated with oral steroids and topical corticosteroids and he made steady recovery of his skin rash. His aripiprazole was stopped for DRESS syndrome concern.

\section{Discussion}

Cutaneous adverse reaction to drugs (SCARs) is a spectrum of diseases that includes acute generalized exanthematous pustulosis (AGEP), drug reaction with eosinophilia and systemic symptoms (DRESS) and epidermal necrolysis (Stevens-Johnson syndrome/toxic epidermal necrolysis (SJS-TEN). Drug reactions are not uncommon in hospitalized patients and affecting $2 \%$ to $3 \%$ [1]. Only a fraction of these reactions (2\%) are considered severe to seek medical attention [1].

These skin conditions have many histological and biological features in common $[2,3]$. Diagnosis of these syndromes is mainly based on clinical grounds, and overlap between the various clinical entities do occur making accurate diagnosis on clinical grounds almost impossible. Most of these syndromes are characterized by

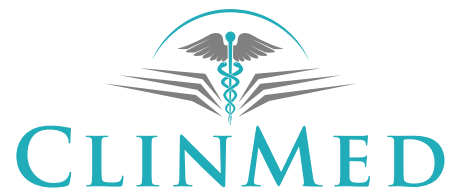

INTERNATIONAL LIBRARY

Citation: Magbri A, Seth H (2017) Drug Rash with Eosinophilia and Systemic Symptoms (DRESS) or StevensJohnson Syndrome (SJS): Does the Name Matter! J Clin Nephrol Ren Care 3:023. doi.org/10.23937/25723286.1510023

Received: February 03, 2017: Accepted: April 10, 2017: Published: April 13, 2017

Copyright: (c) 2017 Magbri A, et al. This is an open-access article distributed under the terms of the Creative Commons Attribution License, which permits unrestricted use, distribution, and reproduction in any medium, provided the original author and source are credited. 
a latency period of 2-6 weeks between the exposure to drug and the cutaneous findings which is required for type-IV hypersensitivity to develop. Cutaneous manifestations are common and present in $70 \%-100 \%$ of cases.

Eosinophilia is considered the most frequently occurring hematological abnormality (>50\%) of the cases. Other hematological abnormalities observed were thrombocytopenia, anemia, neutropenia, and the presence of large activated atypical lymphocytes.

Hepatic involvement in the form of hepato-cellular necrosis with high liver enzymes was the most common visceral abnormalities encountered in these cases. Renal dysfunction in the form of proteinuria, decreased renal functions, and high creatinine were observed most often with allopurinol and other antibiotics. Minocycline causes eosinophilic pneumonitis (33\%) of the cases [4]. It was speculated that the different symptoms associated with each drug were in some way related to the degree of chemical specificity and its reactive metabolites that accumulate in the bodily systems [5].

AGEP drug reaction is presented with pustular eruption that occurs soon after drug administration. The usual offending drugs are, aminopenicillin, pristinamycin, diltiazem $[6,7]$.

DRESS syndrome on the other hand, is also known as drug-induced hypersensitivity syndrome. It is a severe, systemic drug reaction with dermal eosinophilia, and internal organ involvement (liver, kidney, heart). It is characterized by high fever, facial edema, lymphadenopathy, and morbilliform rash. This rash can progress to involve large part of the skin with erythematous reaction and exfoliative dermatitis [8-10].

Overlap syndrome between SCARs do occur e.g. AGEP can presented with facial edema, atypical blisters and mucous involvement $[6,11,12]$. Cases similar to SJS-TEN with eosinophilia have been also described $[13,14]$. Internal organ involvement is not common in AGEP even through lymphadenopathy, slight elevation of liver enzymes, and reduced creatinine clearance may be observed $[6,15]$.

DRESS syndrome can also be confused with SJS-TEN on clinical grounds, as pustules may be found in $20 \%$ of cases [16]. Vesicles, blisters, atypical target lesions and mucous membrane involvement have been reported $[8,16]$. Cases of overlap syndrome between DRESS and TEN have also been reported in the literature, making accurate classification of these SCARs difficult if not impossible under certain circumstances [17]. Clinicians may have difficulty diagnosing these SCARs with certainty. Bouvresse, et al. [18], for example, reported that $7 / 10$ of their patients could not be classified because several diagnoses of SCARs were possible. If we consider these diseases as a spectrum of severity, on one hand mild drug reaction with mild skin involvement and excellent prognosis, and on the other end of the spectrum severe symptoms with systemic and skin manifestation that poses a grave risk with high morbidity and mortality like SJS-TEN.

The conventional criticism to this paper is that distinguishing between the different entities of drug reaction is important for diagnosis and management. However, I would argue that in many of these cases tissue biopsy are rarely taken and treatment principles are the same and differed only according to the severity of illness.

In conclusion, for patients with severe skin reaction due to drugs, determining and removing the offending drug is more important than a precise diagnosis. Complications are very rare after AGEP, but are infrequent after DRESS which is mostly auto-immune [19]. These complications are nearly always present after SIS-TEN [20]. Due to the severity of the disease process, the mortality rate can vary, $2 \%$ in AGEP and up to (20\%-25\%) in SJS-TEN [21]. Since most of these SCARs are due to participation of T-cell with type-IV delayed hypersensitivity reaction it might be logical to consider these diseases as one spectrum ranging from mild (AGEP) to severe (SIS-TEN). An improved term that encompasses all these disorders may be "Skin and Systemic Hypersensitivity Adverse Reaction (SHARE) syndrome".

The authors have no financial disclosure.

\section{References}

1. Wolf R, Orion E, Marcos B, Matz H (2005) Life-threatening acute adverse Cutaneous drug reactions. Clin Dermatol 23: 171-181.

2. Roujeau JC, Stern RS (1994) Severe adverse Cutaneous reaction to drugs. N Engl J Med 331: 1272-1285.

3. Valeyrie-Allanore L, Sassolas B, Roujeau JC (2007) Drug-induced skin, nail, and hair disorders. Drugs Saf 30: 10111030.

4. Choudhary S, McLeod M, Torchia D, Romanelli P (2013) Drug reaction with eosinophilia and systemic symptoms (DRESS) syndrome. J Clin Aesthetic Dermatology 6: 31-37.

5. Peyriere $H$, Dereure $O$, Breton $H$, Demoly $P$, Cociglio $M$, et al. (2006) Variability in the clinical pattern of Cutaneous side-effects of drugs with systemic symptoms: does DRESS syndrome really exixt? Br J Dermatol 155: 422-428.

6. Sidoroffe A, Halevy S, Bavinck JN, Vaillant L, Roujeau JC (2001) Acute generalized exanthematous pustulosis (AGEP)-a clinical reaction pattern. J Cutan Pathol 28: 113-119.

7. Sidoroff A, Dunant A, Viboud C, Halevy S, Bavinck JN, et al. (2007) Risk factors for acute generalized exanthematous pustulosis (AGEP)- results of a multinational case-control study (EuroSCAR). Br J Dermatol 157: 989-996.

8. Bocquet H, Bagot M, Roujeau JC (1996) Drug-induced pseudolymphoma and drug hypersensitivity syndrome (Drug rash with Eosinophilia and Systemic Symptoms (DRESS). Semin Cutan Med Surg 15: 250-257.

9. Cacoub P, Musette P, Descamps V, Meyer O, Speirs C, et al. (2011) The DRESS syndrome: a literature review. Am J Med 124: 588-597.

10. Kardaun SH, Sidoroff A, Valeyrie-Allanore L, Halvey S, Davidovici $B B$, et al. (2007) Variability in the clinical pattern of 
Cutaneous side-effects of drugs with systemic symptoms: does a DRESS syndrome really exist? $\mathrm{Br} \mathrm{J}$ Dermatol 156: 609-611.

11. Roujeau JC, Bioulac-Sage P, Bourseau C, Guillaume JC, Bernard $P$, et al. (1991) Acute generalized exanthematous pustulosis: analysis of 63 cases. Arch Dermatol 127: 1333-1338.

12. Speeckaert MM, Speeckaert R, Lambert J, Brochez L (2010) Acute generalized exanthematous pustulosis: an overview of the clinical, immunological, and diagnostic concepts. Eur J Dermatol 20: 425-433.

13. Peermohamed S, Haber RM (2011) Acute generalized pustulosis simulating toxic epidermal necrolysis: a case report and review of the literature. Arch Dermatol 147: 697-701.

14. Machet ML, Vaillant $L$ (2011) Acute generalized pustulosis. Ann Dermatol Venereol 128: 73-79.

15. Kleier RS, Breneman DL, Boilko S (1991) Generalized postulation as a manifestation of the anticoagulant hypersensitivity syndrome. Arch Dermatol 127: 1361-1364.

16. Begon E, Roujeau JC (2004) Drug hypersensitivity syndrome: DRESS (drug reaction with eosinophilia and systemic symptoms). Ann Dermatol Venereol 131: 293-297.
17. Wolf R, Davidovici B, Matz H, Mahlab K, Orion E, et al. (2006) Drug rash with eosinophilia and systemic symptoms versus Stevens-Johnson Syndrome- a case that indicates a stumbling block in the current classification. Int Arch Allergy Immunol 141: 308-310.

18. Bouvresse S, Valeyrie-Allanore L, Ortonne N, Konstantinou MP, Kardaun SH, et al. (2012) Toxic epidermal necrolysis, DRESS, AGEP: Do overlap cases exist? Orphanet $\mathrm{J}$ of Rare Diseas 7: 72.

19. Funck-Berntano E, Uong T, Famil D, Bouaziz JD, Ortonne $\mathrm{N}$, et al. (2011) Auto-immune thyroiditis and drug reaction with eosinophilia and systemic symptoms (DRESS) associated with HHV-6 viral reactivation. Ann Dermatol Venereol 138: 580-585.

20. Geudry J, Roujea JC, Binaghi M, Soubrane G, Muraine M (2009) Risk factors for the development of ocular complications of Stevens-Johnson syndrome and toxic epidermal necrolysis. Arch Dermatol 145: 157-162.

21. Mockenhaupt M, Viboud C, Dunant A, Naldi L, Halevy S, et al. (2008) Stevens-Johnson syndrome and toxic epidermal necrolysis: assessment of medication risks with emphasis on recently marketed drugs. The EuroScar-study. J Invest Dermatol 128: 135-144. 